\title{
Management of idiopathic dilated cardiomyopathy with intramyocardial stem cell transplantation in children: a retrospective study of 7 patients
}

\author{
Aris Lacis ${ }^{1, ~ *}$, Inguna Lubaua ${ }^{2}$, Andrejs Erglis ${ }^{3}$, Andis Lacis ${ }^{2}$, Inta Bergmane ${ }^{1}$ \\ ${ }^{1}$ Clinic of Pediatric Cardiology and Cardiac Surgery, University Children Hospital, Riga, Latvia \\ ${ }^{2}$ Riga Stradins University, Riga, Latvia \\ ${ }^{3}$ Latvian Institute of Cardiology, Riga, Latvia
}

Email address:

aris.lacis@apollo.lv(A. Lacis), inguna.lubaua@rsu.lv(I. Lubaua)

To cite this article:

Aris Lacis, Inguna Lubaua, Andrejs Erglis, Andis Lacis, Inta Bergmane. Management of Idiopathic Dilated Cardiomyopathy with Intramyocardial Stem Cell Transplantation in Children: A Retrospective Study of 7 Patients. Science Journal of Clinical Medicine. Vol. 2, No. 4, 2013, pp. 129-133. doi: 10.11648/j.sjcm.20130204.12

\begin{abstract}
This retrospective report presents findings on 7 patients with idiopathic dilated cardiomyopathy who underwent transplantation of autologous bone marrow derived mononuclear cells (BMSC) after failed routine conservative treatment, and were on a waiting list for cardiac transplantation. In two out of seven patients, we performed intramyocardial delivery of BMSC twice, 22 and 24 months respectively after the first transplant. All patients received anti-congestive therapy by diuretics, ACE inhibitors, carvedilol, digitalis and aspirin. We discuss potential disadvantages of intracoronary injections of autologous bone marrow stem cells. We believe that our BMSC transplantation method as opposed to intravascular input is the method of choice, particularly in children with idiopathic dilated cardiomyopathy because it is safe, gentle and is not associated with risks for coronary circulation.
\end{abstract}

Keywords: Idiopathic Dilated Cardiomyopathy (IDCM) In Children, Bone Marrow Stem Cells (BMSC), Intramyocardial BMSC Transplantation

\section{Introduction}

Dilated cardiomyopathy (DCM) is a serious problem in pediatric cardiology. Despite the relatively low incidence 0 , $57 / 100000$ to $2,6 / 100000$ children, the mortality rate is high: one third of patients die within a first year after diagnosis $(1,2)$. Up to $40 \%$ of them are diagnosed idiopathic dilated cardiomyopathy (IDCM) - defined as left ventricular dilatation and systolic dysfunction of unknown cause. The prognosis is poor in pediatric patients, and survival appears to be related to the degree of systolic dysfunction. Conservative treatment does not provide substantially better prognosis. Heart transplantation appears to be the last resort option for these patients, however the lack of donors remains an important limitation for this procedure. Furthermore, these patients do not live long enough to undergo heart transplantation, at least partly due to delay in diagnostics.

Recent clinical studies $(3,4)$ suggested that bone marrow-derived autologous mononuclear cells or circulating progenitor cells $(5,6)$ may be a promising therapy for management of these patients. Since the first clinical trial published in 2001 by Menasche et al. (7) a lot of trials have been reported, but till the year 2012 only four reports with a limited amount of patients were published $(3,4,5,6)$. Mentioned trials experimented with different routes of delivery, including direct intramyocardial injection at the time of coronary artery bypass grafting $(8,9)$, intra-coronary infusion $(3,4,5,6)$ and percutaneous endocardial injection using devices such as the NOGA catheter $(10,11,12)$.

\section{Materials and Methods}

We have started intramyocardial stem cell transplantation in collaboration with The Latvian Center of Cardiology, Pauls Stradins Clinical University Hospital and Cell Transplantation Center in May, 2009. As a prerequisite in all cases, we obtained a written informed consent from the patient's parents and a permission from the Ethics Committee to perform the BMSC transplantation. Cell suspension 
preparation: manufacturing is performed at the Latvian Laboratory of Cell Transplantation of Pauls Stradins Clinical University Hospital. The manufacturing procedures are in compliance with principles of good manufacturing practices as set out in Directive 2003/94/EC (3-year experience in processing biological medical products). A manufacturing authorization, Certificate $\mathrm{Nr}$. AO-3, registration $2453 / 3817$, includes manufacturing of bone marrow derived cell therapy products. In total, there were 17 patients with dilated cardiomyopathy admitted to our center since the year 2000. Six of them died, two became adults, one underwent the Batista procedure and one demonstrated clinical recovery. All the patients received conservative treatment of heart failure prior to the BMSC transplantation. The decision to perform the BMSC transplantation was based on perspective condition of the patient and possibilities for heart transplantation. Following detailed and repeated check-ups of the first patient during one year after the transplant, we made a decision to use the stem cell therapy in other patients as well. Already seven patients at the age from 4 months to 17 years and weight from 5 to 61 kilograms have undergone the transplantation of BMSC. Three of them at the procedure were were 4 months old. We chose patients with severely and moderately decreased heart ejection fraction. We used $2 \mathrm{D}$ and $3 \mathrm{D}$ echocardiography to evaluate impairment of heart function. We found LVDd more than 2SD in Z-score, decreased FS $(<27 \%)$ and $\mathrm{EF}(<45 \%)$. The inflammatory and autoimmune processes were excluded by laboratory investigations (WBC, $\mathrm{CRO}$, ANA at normal range). All the patients underwent genetic tests to exclude genetically determined metabolic disorders. Laboratory tests did not reveal the presence of viral (RSV, adeno, parvo B19, entero, CMV, EBV, rubella, rubeola) antibodies in all the patients. For diagnostic purposes, we performed transvenous endomyocardial biopsy via the femoral vein in 2 patients. The histological investigation of biopsy material revealed hypertrophy of myocytes and fibrosis. All patients received massive anti-congestive therapy by diuretics, ACE inhibitors, carvedilol, digitalis, and aspirin.

\subsection{Preparation of Bone Marrow Aspirate}

We aspirated 5 to 30 milliliters of bone marrow from the iliac crest to isolate 17 to 122 million bone marrow cells (BMSC). We took samples for flow cytometry from $15 \mathrm{ml}$ of mononuclear cell fraction and prepared for transplantation. Then we carried out preparation of the isolated cells by using Stem-kitTM reagents (Cat. Nr. IM3630; Beckman Coulter) that contained CD34-PE, CD45-FITCm isotype control, 7AAD (viability dye) and Stem-Count Fluorospheres, followed by FACS analysis on FC-500 (Beckman Coulter), using CXP analysis software. Each measurement contained at least 50000 events. Maximum number of events was 100 000 . Obtained numbers of cells $/ \mu \mathrm{L}$ were calculated for the total number of CD34+ cells within transplantation material.
We excluded from the study measurements with less than 50 000 events.

\subsection{Method of Stem Cell Transplantation}

The material as suspension of physiologic saline was given to patients by intramyocardial puncture in two doses, $1 \mathrm{ml}$ each to minimize risks of possible periprocedural lesions. The procedure was performed under general anesthesia and echocardiographic control at the operating theatre. We used subxiphoidal approach for transcutaneous injection of the suspension into the septum or apex of heart, avoiding punctures of the ultra-thin right ventricular wall. The $0,95 \times 220 \mathrm{~mm}$ CHIBA needle was used for injection. We observed no periprocedural complications.

\subsection{Follow-Up}

We performed repeated check-ups for all patients every second month after the BMSC transplantation, including physical examination, electrocardiography (ECG) and transthoracic echocardiography. Six or our patients had a complete one year follow-up period, analyzed in the present study. The statistical significance was determined by t-Test $(\mathrm{p}<0.05)$.

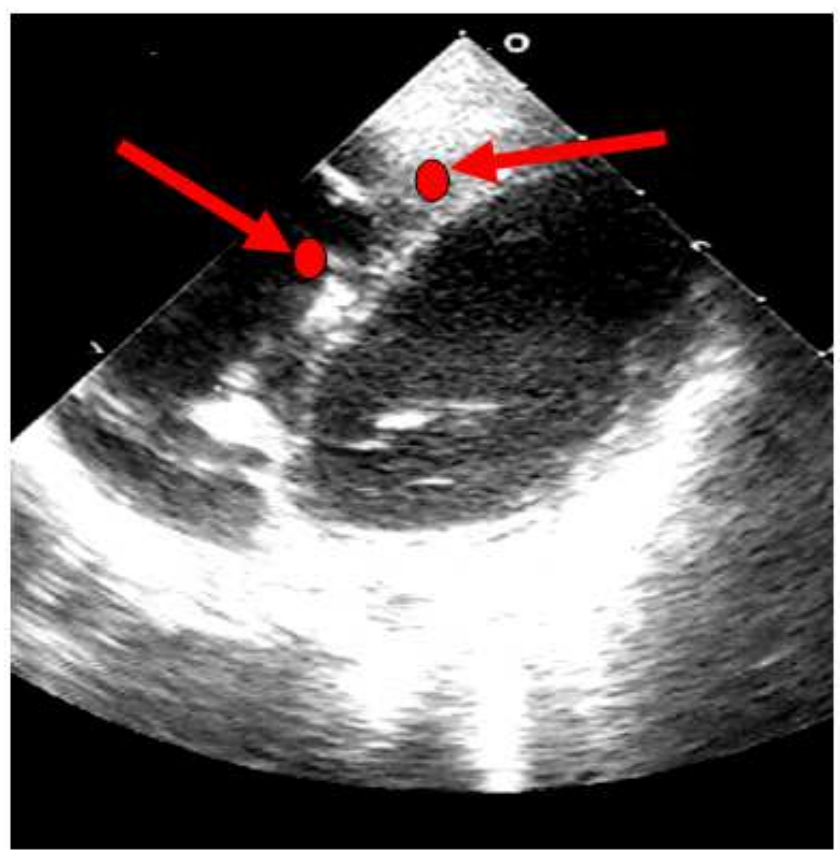

Figure 1. Suggested sites for cell delivery into septum or apex of heart under echo control.

\section{Results}

Within one year after BMSC transplantation, we observed increase of ejection fraction (EF). With the average baseline EF was 33,5\%, we observed increase up to $54 \%$ $(\mathrm{p}=0.00154)$ in the 6-month period and up to 54,5\% $(p=0.00315)$ after one year. The difference between base- 
line data and results after 6 and 12 months was statistically significant, but there was no significant difference between 6-month and 12-month data (CI-95\%).

Also, there was correlation observed in ECG and echo improvement and cardio-thoracic ratio (CTR) decrease. (From average 63, 2 to 55, 5; $\mathrm{p}=0.016$ ).

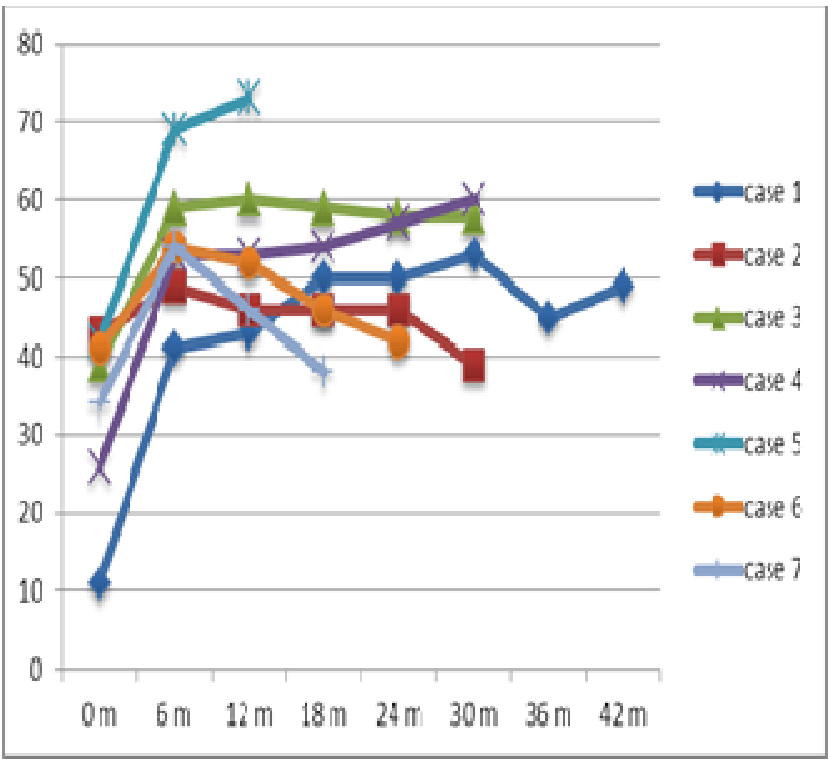

Figure 2. Increase of ejection fraction after BMCS transplantation.

The left ventricular overload registered with ECG gradually decreased. The CTR in chest X-ray decreased by $11 \%$ (from average 63,2 to 55,5; $\mathrm{p}=0.016$ ). The clinical status of patients improved from class III-IV to I-II (NYHA). The most impressive improvements were observed in patients with the worse baseline status and lowest ejection fraction before the procedure. Although EF increased in all patients, some of them failed to demonstrate a reduction of left ventricular diastolic dysfunction. There were observed no periprocedural side effects or heart rhythm alterations.

\section{Discussion}

The current gold standard for treatment of dilated cardiomyopathy is the heart transplantation securing good long-term results $(13,14)$. Unfortunately, the transplantation is limited due to the absence of suitable donors. Of course, the ventricular assisting device is the way of bridging to transplantation. Both methods are expensive procedures and need lots of resources $(15,16)$. Other surgical options are resynchronization therapy and Batista procedure. The resynchronization is a promising method and is considered as an alternative to delay the heart transplantation, as for Batista procedure, the European Society of Cardiology guidelines not recommended it for treatment of dilated cardiomyopathy (17).

Talking about endomyocardial biopsies, the views are quite divergent. The analysis of some literature data shows that endomyocardial biopsy is not suitable for diagnosis, therapy, and detection of early stages or prognostic evaluation in the dilated cardiomyopathy, whereas other investigators suggest that endomyocardial biopsy in children remains an important evaluation criteria for cardiomyopathy $(18,19)$. We believe that the need for biopsy should be carefully evaluated due to high risk of myocardial perforation, especially in infants. We were trying to find another way to help patients with no access to either ventricular assist device (VAD) or heart transplantation. Unfortunately, there are just a few study reports on the use of stem cell transplantation in children with dilated cardiomyopathy. In our study we observed the increase of cardiac function similar to results in study reports from Rupp et al., Olguntürk et al., Smits et al. Better results were observed in subgroups of younger patients and those who received stem cell transplantation shortly after the onset of the disease, as opposed to patients after prolonged conservative therapy before receiving the transplant. Our own experience demonstrates that the most impressive improvement in cardiac function was observed in patients who particularly poor baseline data $(20,21)$. All this provides the basis for future research to establish the optimal timing for stem cell transplantation.

In the meantime, the issue about the role of cell transplantation in myocardial restoration remains unresolved. There is quite extensive research data available on potential role of stem and progenitor cells in management of ischemic heart disease. Murry et al., Heil et al. suggest the potential of bone marrow cells to promote paracrine effects in the ischemic tissues (e.g. secretion of angiogenic factors), and suggest that paracrine signaling, rather than cell incorporation, promotes functional recovery $(22,23)$. Taghavi and George conclude that progenitor cells have the capability to home myocardium in response to ischemia (24). Cell adhesion markers, in particular integrins, play an important role in the trafficking of stem cells to myocardium. In addition, damaged myocardium secretes several chemokines and growth factors that recruit these precursor cells to the heart. Several studies have shown the role of different growth factors involved in the homing of stem cells to ischemic myocardium: stem cell factor (25), vascular endothelial growth factor (26), neural growth factor (27), granulocyte-colony stimulating factor (28), insulin-like growth factor (29), hepatocyte growth factor (30), fibroblast growth factor (31).

Several experimental studies have established a role of endothelial nitric oxide (eNOS) synthase as an essential component for neovascularization (32). Evidently, eNOS influences recruitment of stem and progenitor cells which may be considered contributing to impaired regeneration processes in ischemic heart disease patients, who are characterized by a reduced systemic nitric oxide bioactivity. Erythropoietin has also been shown to improve cardiac function by inducing neovascularization. Investigators suggest this neovascularization appears to be related to increased mobilization and incorporation of bone marrow derived endothelial progenitor cells. Erythropoietin has 
been shown to lead to preferential homing of endothelial progenitor cells to the ischemic border zone of myocardial infarcts resulting in improved microvascularization of ischemic cardiac tissue (33).

It still remains to be clarified, which way of administration of stem cells is the safest and most effective. As reported by Schächinger et al., in patients after myocardial infarction undergoing intracoronary infusion of (111)In-oxine-labeled proangiogenic progenitor cells, a substantial amount of radioactivity is detected for several days in the heart, indicating homing of progenitor cells to the myocardium (34). Yet the amount of proangiogenic progenitor cells retained in the heart decreased progressively with time after the acute myocardial infarction. The study data suggest that proangiogenic progenitor cells preferentially home to extensive acute myocardial infarcts characterized by low viability and reduced coronary flow reserve. Schots et al. report on rapidly diminishing concentration of intracoronary-injected CD133+ peripheral blood progenitor cells in two patients, where detailed analysis showed $6.9 \%$ to $8.0 \%$ (after 2 hours) and $2.3 \%$ to $3.2 \%$ (after 12 hours) residual radioactivity at the heart (35). This data may raise concerns whether intravascular injection of stem cells secures sufficient concentration in target tissues causing expected favorable effects. Though, it is equally true that there is no established relationship between exposure time and documented clinical efficacy of injected stem cells.

Another concern regarding intracoronary infusion of stem cells regards possible risks related to the procedure. De Rosa et al., based on their study results conclude that intracoronary infusion of progenitor cells can be performed with adequate safety in patients with acute myocardial infarction or chronic heart failure, though cell-based therapies require intracoronary or intracardiac instrumentation, potentially associated with periprocedural risks such as vessel injury in the access site and coronary complications (36).

\section{Conclusions}

Within two years after the onset, symptomatic dilated cardiomyopathy requires heart transplantation in almost half of affected children and is associated with high risk of fatal outcome. However, intramyocardial stem cell transplantation has become a promising therapeutic option.

In general, proposed method of transcutaneous intramyocardial stem cell transplantation for management of IDCM poses low risk and offers significant benefit for critically ill pediatric patients when other therapeutic options are limited or not available at all. On top of lessening the mortality of patients waiting for suitable donors, this method provides a viable chance to stabilize the patients followed by possible removal from the heart transplantation list with NYHA class I status.

It can also be concluded, that survival benefits continue to outweigh the risks related to intramyocardial stem cell transplantation if performed by experienced cardiac surgeons in appropriate hospital setting, provided optimal selection of time, cell types and routes of delivery. We believe that our BMCS transplantation method as opposed to intravascular input is the method of choice, particularly in children with IDCM because it is safe, gentle and is not associated with risks for coronary circulation.

More clinical trials are needed though, in order to establish the role of stem cells in recovery of patients with IDCM.

\section{References}

[1] Alvarez J., Wilkinson J. D., Lipshultz S. E. The Pediatric Cardiomiopathy Registry Study Group. Outcome predictors for pediatric dilated cardiomyopathy: A systemic review. Prog Pediatr Cardiol, 2007:25-32.

[2] Arola A., Tuominen J., Ruuskanen O., Jokinen E. Idiopathic dilated cardiomyopathy in children: prognostic indicators and outcome. Pediatrics, 1998; 101(3 Pt 1):369-76.

[3] Rupp S., Bauer J., Tonn T., et al. Intracoronary administration of autologous bone marrow-derived progenitor cells in a critically ill two-yr-old child with dilated cardiomyopathy. Pediatr Transplant, 2009;13(5):620-3.

[4] Limsuwan A., Hongeng S., Khowsathit P., et al. Transcoronary bone marrow-derived mononuclear progenitor cells. Cardiol Young, 2010;20,Suppl 1:336.

[5] Olguntürk R., Kula S., Sucak G. T., et al. A. Peripheric stem cell transplantation in children with dilated cardiomyopathy: preliminary report of first two cases. Pediatr Transplant, 2010;14(2):257-60.

[6] Rivas J., Menedez J. J., Arrieta R., et al. Usefulness of intracoronary therapy with progenitor cells in patients with dilated cardiomyopathy: Bridge or alternative to heart transplantation. Anales de pediatria, 2011;74(4):218-25.

[7] Menasche P., Hagege A. A., Scorsin M., et al. Myoblast transplantation for heart failure. Lancet, 2001;357:279-80.

[8] Hamano K., Nishida M., Hirata K., et al. Local implantation of autologous bone marrow cells for therapeutic angiogenesis in patients with ischemic heart disease: clinical trial and preliminary results. Jpn. Circ. J., 2001;65:845-7.

[9] Stamm C., Westphal B., Kleine H. D., et al. Autologous bone-marrow stem cell transplantation for myocardial regeneration. Lancet, 2003;361:45-6.

[10] Tse H. F., Kwong Y. L., Chan J. K., et al. Angiogenesis in ischemic myocardium by intramyocardial autologous bone marrow mononuclear cell implantation. Lancet, 2003;361:47-9.

[11] Smits P. C., van Geuns R. J., Poldermans D., Bountioukas M. Catheter-based intramyocardial injection of autologous skeletal myoblasts as a primary treatment of ischemic heart failure: Clinical experience with six-month follow-up. J. Am. Coll. Cardiology, 2003;42:2063-9.

[12] Perin E. C., Dohmann H. F., Borojevic R., et al. Transendocardial, autologous bone marrow cell transplantation for severe chronic ischemic heart failure. Circulation, 
2003; 107:2294-2302.

[13] Minami K., von Knyphausen E., Niino T., et al. Long-term results of pediatric heart transplantation. Ann Thorac Cardiovasc Surg, 2005 Dec;11(6):386-90.

[14] Towbin J. A. Cardiomyopathy and heart transplantation in children. Curr Opin Cardiol, 2002;17(3):274-9.

[15] Lindenfeld J., Kelley P. A. The mechanical heart in Felix B. Engeli "Heart regeneration",pp.270-92. World Scientific Publ. Co Pte. Ltd. 2012. Singapore.

[16] Pauliks L. B., Undar A. New devices for pediatric circulatory support. Curr Opin Cardiol, 2008;23(2)91-6.

[17] ESC guidelines for the diagnosis and treatment of acute and chronic heart failure. 2008.

[18] Cowley C. G., Lozier J. S., Orsmond G. S., Shaddy R. E. Safety of endomyocardial biopsy in children. Cardiol Young, 2003 Oct;13(5):404-7.

[19] Kuhn H., Lawrenz T., Beer G. Indication for myocardial biopsy in myocarditis and dilated cardiomyopathy. Med Klin (Munich), 2005 Sep 15;100(9):553-61.

[20] Lacis A., Erglis A. Intramyocardial administration of autologous bone marrow mononuclear cells in a critically ill child with dilated cardiomyopathy. Cardiology in the Young,2011,21,110-12.

[21] Lacis A., Bergmane I., Ozolins V., et al. Preliminary results of using stem cells transplantation for pediatric patients in case of dilated cardiomyopathy. A Cardiovascular Multimedia Journal, 2010,13, Suppl.2, p.117.

[22] Murry C.E., Soonpaa M.H., Reinecke H., Nakajima H., Nakajima H.O., Rubart M., et al. Haematopoietic stem cells do not transdifferentiate into cardiac myocytes in myocardial infarcts. Nature, 2004;428(6983):664-8.

[23] Heil M., Ziegelhoeffer T., Mees B., Schaper W. A different outlook on the role of bone marrow stem cells in vascular growth: bone marrow delivers software not hardware. Circ Res, 2004;94(5):573-4.

[24] Taghavi S., George J.C. Homing of stem cells to ischemic myocardium. Am J Transl Res, 2013; 5(4): 404-11.

[25] Bodine D., Seidel N., Gale M., et al. Efficient retrovirus transduction of mouse pluripotent hematopoietic stem cells mobilized into the peripheral blood by treatment with granulocyte colony-stimulating factor and stem cell factor. Blood,
1994;84:1482-91.

[26] Shintani S., Murohara T., Ikeda H., et al. Mobilization of endothelial progenitor cells in patients with acute myocardial infarction. Circulation, 2001;103:2776-9.

[27] Meloni M., Caporali A., Graiani G. et al. Nerve growth factor promotes cardiac repair following myocardial infarction. Circulation Research, 2010;106:1275-84.

[28] Zohlnhofer D., Ott I., Mehilli J., et al. Stem cell mobilization by granulocyte colony-stimulating factor in patients with acute myocardial infarction. JAMA, 2006;295:1003-10.

[29] Rota M., Padin-Iruegas M.E., Misao Y., et al. Local activation or implantation of cardiac progenitor cells rescues scarred infarcted myocardium improving cardiac function. Circ Res, 2008;103:107-16.

[30] Urbanek K., Rota M., Cascapera S, et al. Cardiac stem cells possess growth factor-receptor systems that after activation regenerate the infarcted myocardium, improving ventricular function and long-term survival. Circ Res, 2005;97:663-73.

[31] Wang Y., Johnsen H.E., Mortensen S., et al. Changes in circulating mesenchymal stem cells, stem cell homing factor, and vascular growth factors in patients with acute ST elevation myocardial infarction treated with primary percutaneous coronary intervention. Heart, 2006;92:768-74.

[32] Aicher A., Heeschen C., Mildner-Rihm C., et al. Essential role of endothelial nitric oxide synthase for mobilization of stem and progenitor cells. Nat Med, 2003 Nov;9(11):1370-6.

[33] Westenbrink B.D., Lipsic E., Van der Meer P., et al. Erythropoietin improves cardiac function through endothelial progenitor cell and vascular endothelial growth factor mediated neovascularization. Eur Heart J, 2007;28:2018-27.

[34] Schächinger V., Aicher A., Döbert N., et al. Pilot trial on determinants of progenitor cell recruitment to the infarcted human myocardium. Circulation, 2008 Sep 30; $118(14): 1425-32$

[35] Schots R., De Keulenaer G., Schoors D., et al. Evidence that intracoronary-injected CD133+ peripheral blood progenitor cells home to the myocardium in chronic postinfarction heart failure. Exp Hematol, 2007 Dec; 35(12):1884-90.

[36] De Rosa S., Seeger F.H., Honold J., et al. Procedural safety and predictors of acute outcome of intracoronary administration of progenitor cells in 775 consecutive procedures performed for acute myocardial infarction or chronic heart failure. Circ Cardiovasc Interv, 2013 Feb; 6(1):44-51. 